\title{
Photochemical Pollution Indicators in the Subtropics
}

\author{
Leo Klasinc, ${ }^{\text {a,c,* }}$ Tomislav Cvitaš, ${ }^{\mathrm{b}}$ Sean P. McGlynn, ${ }^{\mathrm{c}}$ Min Hu, ${ }^{\mathrm{d}}$ \\ Xiaoyan Tang, ${ }^{d}$ and Yuanhang Zhang ${ }^{d}$ \\ ${ }^{a}$ Ruđer Bošković Institute, Bijenička cesta 54, HR-10000 Zagreb, Croatia \\ ${ }^{\mathrm{b}}$ Department of Chemistry, Faculty of Science, University of Zagreb, Horvatovac 102a, HR-10000 Zagreb, Croatia \\ ${ }^{\mathrm{c} C h e m i s t r y}$ Department, Louisiana State University, Baton Rouge, USA \\ ${ }^{\mathrm{d}}$ Peking University, Beijing, China
}

RECEIVED DECEMBER 2, 2010; REVISED JANUARY 28, 2011; ACCEPTED JANUARY 31, 2011

\begin{abstract}
Indicators evaluated from the long-term hourly averages of ozone volume fractions at air monitoring sites are proposed as measures of the photochemical pollution exposure at those sites. These indicators are based on the average of the daily maximum-to-minimum ratio during the period of maximum ozone production and are corrected a), for the average maximum to average total ozone ratio (indicator $P_{1}$ ) and b), for the number of hours the limit ozone volume ratio limit of $80 \mathrm{ppb}$ was exceeded (indicator $P_{2}$ ). These indicators are then combined into $P_{3}$ as their geometrical mean. The rationale for the introduction of a new set of indicators is based on the suspicion that ozone volume fractions do not provide information either on the total daily ozone that is produced or on the fraction of it that has produced other photochemical pollution components despite that ozone correlates quite well with some of them. Unlike the European stations, where every case in excess of the $80 \mathrm{ppb}$ limit occurs within the April to September "growth period", stations in the subtropics have longer periods (e.g. at Greater Baton Rouge (GBR), USA, for 2001 to 2008) are shifted towards later months June to November (e.g. the Pearl River Delta (PRD) in China for 2006). While GBR and the rural PRD stations exhibit indicators close to those of polluted stations in northern Italy (Po Valley), the (sub)urban PRD stations have high photochemical pollution indicators. However, a surprisingly low indicator level occurs for the coastal Hong Kong stations for reasons possibly attributable to the prevailing easterly winds which bring fresh air and airborne sea-salt particulates. (doi: 10.5562/cca1807)
\end{abstract}

Keywords: ambient ozone, photochemical pollution, pollution indicators

\section{IMPLICATIONS}

The proposed indicators represent a new approach to photochemical pollution problems and they permit a very different view of the air quality at particular sites. The proposed pollution indicators might be of interest to law- and policy-makers in that they give a better representation of pollution-related problems than do simple limiting values. Such indicators should also function well in different climatic zones.

\section{INTRODUCTION}

A considerable rise of tropospheric ozone in the subtropics is predicted ${ }^{1,2}$ over the next 100 years. Ozone is a strong oxidant that affects living cells and their constituents, especially those involved in photosynthesis and respiration processes, and, hence, vegetation and human health in general. It also affects numerous other materials prone to oxidation.
Ozone, a typical pollutant in the atmospheric boundary layer of regions with substantial sunshine and vehicle traffic, is relatively easy to measure and has been monitored at many sites for long periods of time. We have recently shown that by a systematic comparison of the accumulated and now widely available 1-hour averages of ambient ozone data from sites in Europe, ${ }^{3}$ particularly ones in the central Mediterranean region (Italy, Slovenia, Croatia), ${ }^{4}$ valuable information on photochemical pollution can be obtained using newly proposed indicators (vide infra). Actually the new indicators are more relevant for photochemical pollution than traditional ozone indices based on daily average or hourly maximum. Since ozone formation is initiated by photo-dissociation of $\mathrm{NO}_{2}$ and since its further production and destruction is facilitated by the presence of volatile organic compounds (VOCs) and particles, ${ }^{5}$ its volume fraction (or mass concentration) shows a pronounced diurnal variation with peak values in the early afternoon and minimum values during rush-hours and

* Author to whom correspondence should be addressed. (E-mail: klasinc@irb.hr) 
night. The daily maximum hourly or longer-term values are used to define indices, limits, directives and standards for air quality with respect to ozone. However, these entities provide little or no information on the total amount of ozone produced daily nor on the amounts of other photochemical pollution components that are subsequently produced in further reactions of ozone with other pollutants present in the air. Ozone concentrations do correlate quite well with some photochemical indices ${ }^{6}$ but these generally represent reactants (precursors) and not the products of reactions with ozone. It is not unusual, for example, that higher altitude stations in remote areas record higher hourly and long-term (8 hours or more) averages than do stations in urban and suburban sites where the significant destruction of ozone decreases the average but often leads to further deterioration of the air quality. Consequently, ozone fractions, on their own, are not valid indicators of photochemical pollution. By assuming that ozone reaction products (e.g. aldehydes, peroxides, radicals and secondary organic aerosols $\left.(\mathrm{SOA})^{7}\right)$ represent very potent pollution components of the ambient air, new pollution indicators were devised by considering the typical diurnal variation of ozone volume fractions. The indicators are based on calculating the ratios of daily maximum-tominimum hourly average ozone fractions, the maxima being representative of ozone formation and the minima of ozone destruction and, hence, of the formation of potentially hazardous compounds. The average of such daily ratios over time periods of interest (e.g. growth season 1 April - 30 September), yields a valid indication of the ozone load along with its reaction products in air. A further correction factor was also applied in order to give a higher weight to the peak ozone values. This was done in two ways: (1), the average ratio is multiplied by the seasonal average of daily maxima divided by the mean for the whole season (indicator $P_{1}$ ) or (2) by accounting for the total time a chosen limiting value (e.g., $80 \mathrm{ppb}$ ) was exceeded (indicator $P_{2}$ ).

One further problem with this procedure had to be solved. When the daily minimum hourly value was measured as zero, thus preventing the calculation of the $\mathrm{max} / \mathrm{min}$ ratio, the ratio was set to 1.25 times the maximum value. This factor was obtained by considering the detection limit and precision of used ozone monitors. Originally, the minimum value was set at 0.4 instead of $0 \mathrm{ppb}$, based on the $1 \mathrm{ppb}$ precision of the monitors ${ }^{4}$ which proved to be too large and yielded very high ratios. Setting the zero value to $0.8 \mathrm{ppb}$, which is equivalent to multiplication of the daily maximum by 1.25 , was found to be a more appropriate correction factor because frequent zero values in the data were often a result of imprecise measurements at very low volume fractions.

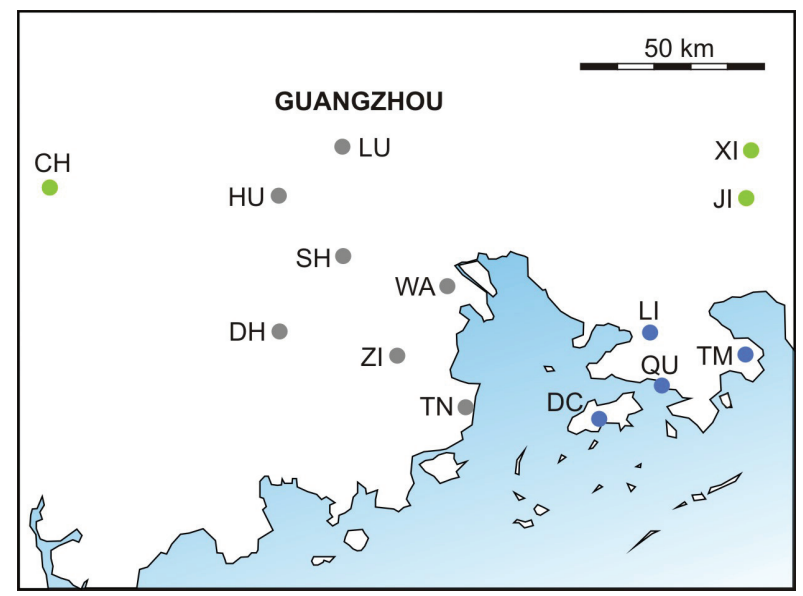

Figure 1. Map of PRD sites indicating rural (green), maritime (blue) and suburban (grey) location.

In order to investigate the incidence of high-ozone episodes at latitudes closer to the tropics, we have analyzed the data for the whole year and compared them with those consecutive six months, the "growth season" in mid-latitudes, that would cover most of the high pollution events. Thus by analyzing ambient ozone data for many European stations, ${ }^{3,4}$ it was found that the $80 \mathrm{ppb}$ ozone limit had been rarely, if ever, exceeded outside the April-September period. One would expect a different seasonal distribution at lower latitudes. Present investigation is aimed to find out how do the new indicators perform in the subtropics, concerning both their value and their seasonal (and growth-seasonal) dependence. It should be mentioned that in the Fourier transform frequency analysis of long-term ozone data the ratio of yearly to daily frequency intensities correlates nicely with the $R$-value of investigated monitoring stations. $^{8,9}$

\section{EXPERIMENTAL METHODS}

The two indicators: $P_{1}=R M / A$ and $P_{2}=R\left(1+168 t_{\mathrm{exc}} / N\right)$, where $R$ is the average of daily maximum-to-minimum ratios, $M$ and $A$ the seasonal average daily maximum and average values, $t_{\mathrm{exc}}$ the time in hours the limit of 80 ppb was exceeded and $N$ the number of measured hourly average fractions. The scaling factor 168 represents the number of hours per week and was chosen so as to multiply $R$ by two when the limiting value was exceeded for one hour per week on the average. The two indicators have been applied here in the analysis of data from three stations Capitol (CAP), Louisiana State University (LSU) and Port Allen (PAL) in the Greater Baton Rouge (GBR) area ${ }^{9}$ in USA for 2001-2008 (http://www.deq.louisiana.gov/portal/Default.aspx?tabid $=2420$ ) and fourteen stations in the Pearl River 
Table 1a. Ozone data for the Baton Rouge area stations for the whole years 2001 to 2008 . (source: http://www.deq.louisiana.gov/portal/Default.aspx?tabid=2420)

\begin{tabular}{|c|c|c|c|c|c|c|c|c|c|}
\hline \multicolumn{10}{|c|}{ JAN - DEC } \\
\hline & Year & $A / \mathrm{ppb}$ & $R$ & $M / \mathrm{ppb}$ & $t_{\mathrm{exc}} / \mathrm{h}$ & $P_{1}$ & $P_{2}$ & $P_{3}$ & $N$ \\
\hline \multirow{9}{*}{ 官 } & 2001 & 23.5 & 29.2 & 47 & 56 & 58.5 & 62.1 & 60.3 & 8364 \\
\hline & 2002 & 21.8 & 26.9 & 44 & 34 & 54.3 & 44.8 & 49.3 & 8592 \\
\hline & 2003 & 21.5 & 30.4 & 44 & 58 & 62.1 & 65.0 & 63.5 & 8524 \\
\hline & 2004 & 22.8 & 23.6 & 43 & 35 & 44.5 & 39.9 & 42.1 & 8530 \\
\hline & 2005 & 24.7 & 20.1 & 46 & 48 & 37.4 & 39.0 & 38.2 & 8546 \\
\hline & 2006 & 23.9 & 16.7 & 46 & 42 & 32.1 & 30.3 & 31.2 & 8585 \\
\hline & 2007 & 23.1 & 16.3 & 45 & 31 & 31.8 & 26.2 & 28.9 & 8604 \\
\hline & 2008 & 23.6 & 20.7 & 42 & 5 & 36.8 & 22.8 & 29.0 & 8028 \\
\hline & CAP & 23.11 & 22.98 & 44.6 & 38.8 & 44.7 & 41.3 & 42.8 & 67773 \\
\hline \multirow{9}{*}{ 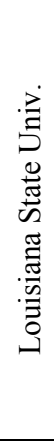 } & 2001 & 23.4 & 21.6 & 46 & 48 & 42.6 & 42.2 & 42.4 & 8472 \\
\hline & 2002 & 22.4 & 27.2 & 45 & 34 & 54.6 & 45.2 & 49.7 & 8607 \\
\hline & 2003 & 23.8 & 30.2 & 49 & 92 & 62.3 & 85.3 & 72.9 & 8514 \\
\hline & 2004 & 26.1 & 27.3 & 49 & 98 & 51.2 & 80.4 & 64.2 & 8439 \\
\hline & 2005 & 28.6 & 27.0 & 54 & 138 & 50.9 & 100.4 & 71.5 & 8506 \\
\hline & 2006 & 28.5 & 16.6 & 53 & 89 & 30.9 & 45.7 & 37.6 & 8546 \\
\hline & 2007 & 26.4 & 17.5 & 50 & 74 & 33.1 & 42.7 & 37.6 & 8601 \\
\hline & 2008 & 25.4 & 24.4 & 46 & 17 & 44.2 & 33.1 & 38.2 & 8074 \\
\hline & LSU & 25.57 & 23.96 & 49.0 & 74.1 & 46.2 & 59.5 & 51.8 & 67759 \\
\hline \multirow{9}{*}{ 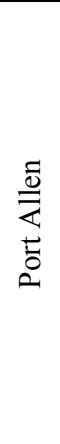 } & 2001 & 23.1 & 31.7 & 47 & 54 & 64.5 & 65.7 & 65.1 & 8463 \\
\hline & 2002 & 23.9 & 18.5 & 46 & 49 & 35.6 & 36.7 & 36.1 & 8393 \\
\hline & 2003 & 24.0 & 29.5 & 49 & 105 & 60.2 & 90.1 & 73.6 & 8583 \\
\hline & 2004 & 24.6 & 24.0 & 47 & 70 & 45.9 & 56.9 & 51.1 & 8595 \\
\hline & 2005 & 26.5 & 26.2 & 50 & 56 & 49.5 & 55.1 & 52.2 & 8555 \\
\hline & 2006 & 26.6 & 16.3 & 50 & 101 & 30.6 & 48.4 & 38.5 & 8617 \\
\hline & 2007 & 23.4 & 16.9 & 45 & 30 & 32.6 & 26.9 & 29.6 & 8564 \\
\hline & 2008 & 23.3 & 20.2 & 43 & 7 & 37.3 & 23.2 & 29.4 & 8110 \\
\hline & PAL & 24.44 & 22.87 & 47.0 & 59.3 & 44.5 & 50.4 & 47.0 & 67880 \\
\hline
\end{tabular}

Delta (PRD) region in southern China for the year 2006. The latter data were collected within the Program of Regional Integrated Experiments on Air Quality over the Pearl River Delta: (PRIDE-PRD-2006). All stations (Figure 1) were provided by automatic ozone monitors and were logged as average hourly volume collected at all fractions. All stations (PRD $21.5^{\circ}-24^{\circ} \mathrm{N}$, GBR around $30^{\circ} \mathrm{N}$ ) fulfill the subtropical condition. The indicator $P_{3}=\sqrt{P_{1} \cdot P_{2}}$, introduced recently ${ }^{4}$ as more robust to variations than $P_{1}$ and $P_{2}$, is also given.

\section{RESULTS}

The results for all stations consist of the following annualized items: averages of the ozone volume fraction
$(A / \mathrm{ppb})$, the corresponding average of the daily maximum-to-minimum ratios $(R)$, the average of daily maxima $(M / \mathrm{ppb})$, the time (in hours) the $80 \mathrm{ppb}$ limit is exceeded $\left(t_{\text {exc }} / \mathrm{h}\right)$, the calculated photochemical pollution indicators $P_{1}$ and $P_{2}$, their geometric mean $P_{3}=\sqrt{P_{1} \cdot P_{2}}$ and the number of hourly values $(N)$ for a, the whole year and for $b$, the six consecutive months with the highest photochemical pollution are given for the GBR area in Tables $1 \mathrm{a}$ and $1 \mathrm{~b}$ and for the Pearl River Delta area in Tables $2 \mathrm{a}$ and $2 \mathrm{~b}$, respectively.

The chosen mid-latitude growth season (1 April to 30 September) covers almost all the events (91\%) within which the $80 \mathrm{ppb}$ limit was exceeded at the three (sub)urban stations in the GBR area and the data are similar to those from polluted sites along the river Po in 
Table 1b. Ozone data for the Baton Rouge area stations for the period 1 April to 30 September with highest photochemical pollution (source: http://www.deq.louisiana.gov/portal/Default.aspx?tabid=2420)

\begin{tabular}{|c|c|c|c|c|c|c|c|c|c|}
\hline \multicolumn{10}{|c|}{ APR - SEP } \\
\hline & Year & $A / \mathrm{ppb}$ & $R / \mathrm{ppb}$ & $M / \mathrm{ppb}$ & $t_{\mathrm{exc}} / \mathrm{h}$ & $P_{1}$ & $P_{2}$ & $P_{3}$ & $N$ \\
\hline \multirow{9}{*}{ 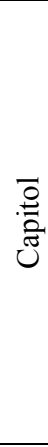 } & 2001 & 26.7 & 33.1 & 53 & 54 & 65.8 & 104.4 & 82.9 & 4213 \\
\hline & 2002 & 25.6 & 34.6 & 53 & 34 & 71.5 & 80.5 & 75.9 & 4307 \\
\hline & 2003 & 24.4 & 35.3 & 51 & 43 & 73.6 & 95.2 & 83.7 & 4255 \\
\hline & 2004 & 25.9 & 26.0 & 49 & 33 & 49.2 & 59.6 & 54.2 & 4292 \\
\hline & 2005 & 30.0 & 19.8 & 56 & 40 & 36.9 & 50.7 & 43.3 & 4295 \\
\hline & 2006 & 27.6 & 19.8 & 54 & 42 & 38.8 & 52.4 & 45.1 & 4295 \\
\hline & 2007 & 26.9 & 18.9 & 52 & 31 & 36.5 & 41.6 & 39.0 & 4316 \\
\hline & 2008 & 25.7 & 21.5 & 47 & 5 & 39.4 & 26.1 & 32.1 & 3970 \\
\hline & $\overline{\text { CAP }}$ & 26.61 & 26.14 & 51.9 & 35.48 & 51.5 & 64.0 & 57.1 & 33943 \\
\hline \multirow{9}{*}{ 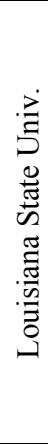 } & 2001 & 26.8 & 19.1 & 51 & 47 & 36.3 & 54.2 & 44.4 & 4285 \\
\hline & 2002 & 26.3 & 32.8 & 53 & 34 & 66.0 & 76.2 & 70.9 & 4315 \\
\hline & 2003 & 27.5 & 33.4 & 56 & 75 & 67.9 & 131.3 & 94.4 & 4304 \\
\hline & 2004 & 30.4 & 29.4 & 58 & 88 & 56.2 & 132.8 & 86.4 & 4212 \\
\hline & 2005 & 34.4 & 36.0 & 65 & 127 & 67.9 & 218.1 & 121.7 & 4211 \\
\hline & 2006 & 32.2 & 19.0 & 61 & 83 & 36.1 & 80.8 & 54.0 & 4294 \\
\hline & 2007 & 30.1 & 19.8 & 58 & 71 & 38.1 & 74.4 & 53.2 & 4312 \\
\hline & 2008 & 27.6 & 25.1 & 50 & 15 & 45.6 & 41.9 & 43.7 & 3783 \\
\hline & LSU & 29.42 & 26.83 & 56.6 & 68.09 & 51.8 & 101.7 & 71.3 & 33716 \\
\hline \multirow{9}{*}{ 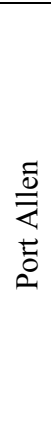 } & 2001 & 25.2 & 39.5 & 51 & 43 & 80.0 & 105.8 & 92.0 & 4303 \\
\hline & 2002 & 27.2 & 25.7 & 54 & 49 & 51.1 & 75.6 & 62.2 & 4242 \\
\hline & 2003 & 26.9 & 33.1 & 55 & 84 & 67.8 & 141.9 & 98.1 & 4300 \\
\hline & 2004 & 27.3 & 27.2 & 52 & 61 & 51.8 & 92.0 & 69.0 & 4296 \\
\hline & 2005 & 30.4 & 36.9 & 58 & 45 & 70.5 & 102.3 & 84.9 & 4272 \\
\hline & 2006 & 30.3 & 20.0 & 58 & 101 & 38.2 & 98.4 & 61.3 & 4321 \\
\hline & 2007 & 26.9 & 19.7 & 53 & 29 & 38.7 & 42.0 & 40.3 & 4299 \\
\hline & 2008 & 25.1 & 25.2 & 47 & 7 & 47.1 & 32.9 & 39.4 & 3817 \\
\hline & $\overline{\text { PAL }}$ & 27.45 & 28.45 & 53.6 & 53.06 & 55.8 & 87.1 & 68.8 & 33850 \\
\hline
\end{tabular}

northern Italy. ${ }^{4}$ When the period was shifted by one month from 1 May to 31 October no significant change was observed. The reason is that both in April 2003 and October 2005 unusually high ambient ozone fractions were measured. It seems, however, that a longer period such as 7 months covering April to October, would take into account all the pollution episodes in any given year.

The data for the 14 PRD-stations (Figure 1) during 2006 reveal three types of sites: first, the rural type stations $\mathrm{CH}, \mathrm{XI}$ and JI which lie at some distance both from the heavily polluted Guangzhou area as well as from the sea; second, the coastal type stations LI, TM, QU and DC within the Hong Kong area; and third, the (sub)urban stations within or affected by the greater metropolitan area of Guangzhou (Table 2).
Ozone data at the rural stations $\mathrm{CH}$, JI and XI show a similar behaviour to the Baton Rouge stations. However, the frequency of high ozone events (above 80 ppb) outside the mid-latitude growth season (AprilSeptember) is much higher here (some $30 \%$ ) but reduces to $15 \%$ when the six-months period is shifted to June-November. Both the USA and the China data suggest that the period of frequent high ozone events at lower latitudes is shifted to later months compared to the European April-September growth season. In addition, the data indicate that the spread of high ozone events becomes wider the further south one goes: the April-September period covers over $95 \%$ of such events in Europe, ${ }^{4,5}$ the same period $91 \%$ in Louisiana, but in the most high ozone abundant June-November 
Table 2a. Ozone data for the Pearl River Delta area (Figure 1, at right) for the whole year 2006

\begin{tabular}{|c|c|c|c|c|c|c|c|c|c|}
\hline \multicolumn{10}{|c|}{ JAN - DEC 2006} \\
\hline & Site & $A / \mathrm{ppb}$ & $R / \mathrm{ppb}$ & $M / \mathrm{ppb}$ & $t_{\mathrm{exc}} / \mathrm{h}$ & $P_{1}$ & $P_{2}$ & $P_{3}$ & $N$ \\
\hline \multirow{4}{*}{ 苛 } & $\mathrm{CH}$ & 21.7 & 16.4 & 47 & 124 & 35.6 & 60.2 & 46.3 & 7830 \\
\hline & XI & 24.7 & 22.4 & 51 & 133 & 46.3 & 82.1 & 61.7 & 8363 \\
\hline & $\mathrm{JI}$ & 32.5 & 13.8 & 57 & 172 & 24.1 & 65.1 & 39.6 & 7750 \\
\hline & & 26.2 & 17.7 & 51.6 & 142.7 & 35.6 & 69.4 & 49.5 & 23943 \\
\hline \multirow{5}{*}{$\begin{array}{l}\bar{\pi} \\
\tilde{\Xi} \\
\tilde{0} \\
0\end{array}$} & LI & 19.1 & 21.2 & 41 & 83 & 45.5 & 61.1 & 52.7 & 7417 \\
\hline & $\mathrm{TM}$ & 34.4 & 7.0 & 55 & 183 & 11.2 & 32.5 & 19.1 & 8503 \\
\hline & QU & 12.5 & 10.9 & 28 & 19 & 24.3 & 15.0 & 19.1 & 8527 \\
\hline & DC & 18.6 & 19.7 & 40 & 77 & 42.2 & 50.2 & 46.0 & 8334 \\
\hline & & 21.2 & 14.5 & 41.0 & 90.8 & 30.2 & 38.9 & 33.5 & 32781 \\
\hline \multirow{8}{*}{ 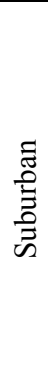 } & LU & 15.4 & 51.5 & 47 & 139 & 157.3 & 213.3 & 183.2 & 7436 \\
\hline & $\mathrm{HU}$ & 17.7 & 30.4 & 52 & 215 & 89.3 & 174.4 & 124.8 & 7630 \\
\hline & $\mathrm{SH}$ & 19.0 & 26.6 & 53 & 285 & 74.2 & 187.0 & 117.8 & 7946 \\
\hline & WA & 21.1 & 34.6 & 54 & 316 & 88.6 & 259.6 & 151.7 & 8164 \\
\hline & $\mathrm{DH}$ & 17.2 & 24.5 & 44 & 180 & 62.9 & 117.6 & 86.0 & 7969 \\
\hline & ZI & 21.2 & 41.0 & 55 & 269 & 106.0 & 302.9 & 179.2 & 7073 \\
\hline & $\mathrm{TN}$ & 23.2 & 19.3 & 51 & 297 & 42.5 & 146.5 & 78.9 & 7578 \\
\hline & & 19.3 & 32.3 & 50.8 & 243.6 & 88.1 & 199.1 & 130.8 & 53796 \\
\hline
\end{tabular}

Table 2b. Equivalent data for the period 1 June to 30 November with highest photochemical pollution

\begin{tabular}{|c|c|c|c|c|c|c|c|c|c|}
\hline \multicolumn{10}{|c|}{ JAN - DEC 2006} \\
\hline & Site & $A / \mathrm{ppb}$ & $R / \mathrm{ppb}$ & $M / \mathrm{ppb}$ & $t_{\mathrm{exc}} / \mathrm{h}$ & $P_{1}$ & $P_{2}$ & $P_{3}$ & $N$ \\
\hline \multirow{4}{*}{ 苣 } & $\mathrm{CH}$ & 25.3 & 17.3 & 55 & 112 & 37.6 & 102.2 & 62.0 & 3841 \\
\hline & XI & 26.4 & 22.3 & 56 & 107 & 47.3 & 119.9 & 75.3 & 4110 \\
\hline & JI & 32.3 & 16.7 & 59 & 118 & 30.5 & 97.5 & 54.5 & 4105 \\
\hline & & 28.1 & 18.8 & 56.7 & 112.3 & 38.5 & 106.6 & 64.0 & 12056 \\
\hline \multirow{5}{*}{ 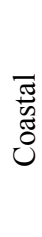 } & LI & 21.5 & 14.9 & 46 & 66 & 31.9 & 59.5 & 43.6 & 3709 \\
\hline & TM & 34.5 & 7.7 & 56 & 153 & 12.6 & 54.3 & 26.2 & 4274 \\
\hline & QU & 13.7 & 12.2 & 31 & 16 & 27.5 & 19.8 & 23.3 & 4268 \\
\hline & DC & 20.3 & 20.1 & 44 & 65 & 43.7 & 72 & 56.1 & 4232 \\
\hline & & 22.5 & 13.7 & 44.2 & 75.4 & 28.8 & 51.1 & 37.0 & 16483 \\
\hline \multirow{8}{*}{ 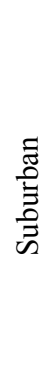 } & LU & 18.4 & 61.2 & 57 & 122 & 189.7 & 403.5 & 276.7 & 3662 \\
\hline & $\mathrm{HU}$ & 21.6 & 36.5 & 63 & 181 & 106.8 & 324.4 & 186.1 & 3860 \\
\hline & $\mathrm{SH}$ & 23 & 37.9 & 66 & 250 & 108.7 & 432.8 & 216.9 & 4028 \\
\hline & WA & 25.6 & 37.3 & 66 & 263 & 96.1 & 436.3 & 204.8 & 4129 \\
\hline & DH & 20.4 & 25.5 & 52 & 161 & 65 & 201.3 & 114.4 & 3923 \\
\hline & ZI & 25 & 38.6 & 64 & 230 & 98.7 & 415.3 & 202.5 & 3954 \\
\hline & $\mathrm{TN}$ & 29.1 & 25.4 & 64 & 255 & 55.9 & 307.7 & 131.2 & 3858 \\
\hline & & 23.4 & 37.3 & 61.8 & 210.2 & 102.2 & 360.9 & 189.9 & 27414 \\
\hline
\end{tabular}

period only $84 \%$ of the events in the PRD. It should be stated that June-July is at PRD the typical "wet" season, while October the "dry" and "polluted" season. It is typical of the subtropics that after a long "winter" a short "spring" is followed by a long "summer" characterized by transport of clean and wet ocean air inland. This is more pronounced at lower latitudes (GBR vs. PRD). Three stations LI, TM, QU and DC at the coast 


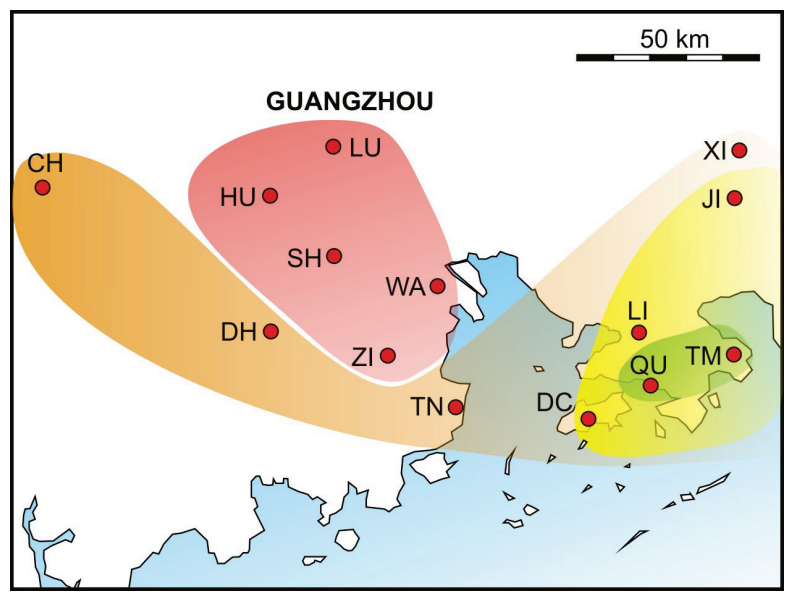

Figure 2. Assessment of photochemical pollution at PRD sites according indicator $P_{3}$ for the whole year 2006 .

of Hong Kong have the lowest photochemical pollution indicators, being quite stable throughout the year. In addition to a possibly cleaner atmosphere, which is supported by the prevailing easterly winds from the sea and other unpolluted areas, a further reason could also be due to ozone destruction on airborne sea-salt particles. The remaining stations $\mathrm{HU}, \mathrm{LU}, \mathrm{SH}, \mathrm{DH}, \mathrm{TN}$, WA and ZI, termed "suburban" here, are characterized by high indicator values $P_{1}, P_{2}$ and $P_{3}$ with LU (190, 404 and 277), SH (109, 433 and 217), and the not much lower WA and ZI exceed the highest values reported so far (i.e., for the Italian station Montelibretti $(128,268$ and 185$)^{3}$ ). They show both higher maximum-tominimum ratios over the season and the limiting value of $80 \mathrm{ppb}$ is exceeded much more frequently. An assessment of the photochemical pollution according the indicator $P_{3}$ values for PRD stations during 2006 is shown in Figure 2. The seven different parameters (i.e. excluding $N$ ) of Table 2a were taken into consideration to create clustering using PCA procedure. Prior to modeling all data were centered to the mean value. The best clustering was obtained using $\mathrm{PC} 1$ and $\mathrm{PC} 2$ The suburban stations form visibly distinct cluster on the other hand rural and coastal station show greater similarity. The main contribution to PC1 can be accounted to descriptors $t_{\mathrm{exc}}, P_{1}, P_{2}$ and $P_{3}$, the main contributors to PC2 are $P_{1}$ and $P_{3}$ and negative contribution of $t_{\text {exc }}$.

\section{CONCLUSIONS}

The subtropics experience the highest ozone values and will find it difficult to comply with any stricter ozone standards ${ }^{10}$. The new indicators presented here perform also in the subtropics when their seasonal characteristics are considered and show to be more, or at least equally, relevant to assess photochemical pollution than traditional ozone indices and should be recommended for air quality management tasks.

Acknowledgments. This work was performed within a Chinese-Croatian bilateral research project on "Ozone monitoring and air quality standards", with the scientific co-operation of the Chemistry Department of LSU, Baton Rouge and with the support of project 098-0982915-2947 of the Ministry for Science, Education and Sports of Croatia. We are grateful to Mrs Vennetta Hayes of LDEQ Air Analysis for the Baton Rouge ozone data, to Professor M. Pompe for the principal component analysis and to Mr Hasan Muharemović for his help with the indicator calculations.

\section{REFERENCES}

1. J. Giles, Nature $\mathbf{4 3 5}$ (2005) 7.

2. D. S. Stevenson, F. J. Dentener, M. G. Schultz, K. van Ellingsen, T. P. C. Noije, O.Wild, W. J. Collins, R. G. Derwent, R. M. Doherty, J. Drevet, H. J. Eskes, A. M. Fiore, M. Gauss, D. A. Hauglustaine, L. W. Horowitz, I. S. A. Isaksen, M, C. Krol, J. -F. Lamarque, M. G. Lawrence, V. Montanaro, J.-F. Muller, G. Pitari, M. J. Prather, J. A. Pyle, S. Rast, J. M. Rodriguez, M. G. Sanderson, N. H. Savage, D. T. Shindell, S. E. Strahan, K. Sudo, S. Szopa, J. Geophys. Res. 111 (2006) D08301.

3. E. Kovač-Andrić, G. Šorgo, N. Kezele, T. Cvitaš, and L. Klasinc, Environ. Monit. Assess. 165 (2010) 577-583.

4. L. Klasinc, T. Cvitaš, A. De Marco, N. Kezele, E. Paoletti, and M. Pompe, Fresenius Env. Bull. 19 (9b) (2010) 1982-1988.

5. B. J. Finlayson-Pitts and J. N. Pitts Jr., Science 276 (2008) 1045 1051.

6. K-H. Tseng, J-L. Wang, M-Y. Cheng, and B-J. Tsuang, Aerosol and Air Quality Res. 9 (2009) 149-171.

7. J. L. Jimenez, M. R.Canagaratna, N. M. Donahue, A. S. H. Prevot, Q. Zhang, J. H. Kroll, P. F. De Carlo, J. D. Allan, H. Coe, N. L. Ng, A. C. Aiken, K. S. Docherty, I. M. Ullbrich, A. P. Grieshop, A. L. Robinson, J. Duplissy, J. D. Smith, K. R. Wilson, V. A. Lanz, C. Hueglin, Y. L. Sun, J. Tian, A. Laaksonen, T. Raatikainen, J. Rautiainen, P. Vaattovaara, M. Ehn, M. Kulmala, J. M. Tomlinson, D. R. Collins, M. J. Cubison, E. J. Dunlea, J. A. Huffman, T. B. Onasch, M. R. Alfarra, P. I. Williams, K. Bower, Y. Kondo, J. Schneider, F. Drewnick, S. Borrmann, S. Weimer, K. Demerjian, D. Salcedo, L. Cottrell, R. Griffin, A. Takami, T. Miyoshi, S. Hatakeyama, A. Shimono, J. Y. Sun, Y. M. Zhang, K. Dzepina, J. R. Kimmel, D. Sueper, J. T. Jayne, S. C. Herndon, A. M. Trimborn, L. R. Williams, E. C. Wood, A. M. Middlebrook, C. E. Kolb, U. Baltensperger, and D. R. Worsnop Science 326 (2009) 1525-1529.

8. T. Cvitaš, M. Furger, R. Girgzdiene, L. Haszpra, N. Kezele, L. Klasinc, A. Planinsek, M. Pompe, A. S. H. Prevot, H. E. Scheel, and E. Schuepbach, J. Geophys. Res. D 109 (2004)

9. L. Klasinc, N. Kezele, M. Pompe, and S. P. McGlynn, Croat. Chem. Acta 81 (2008) 311-318.

10. USEPA (United States Environmental Protection Agency), Revised ozone air quality index. Federal Register 73 (2008) $16436-16515$. 